\title{
PRIMARY BILIARY CIRRHOSIS ASSOCIATION WITH RHEUMATOID ARTHRITIS: A RARE CASE PRESENTATION
}

\author{
Hardeep Singh Deep ${ }^{1}$, Jeetesh Jain ${ }^{2}$, Anumeet S. Grover ${ }^{3}$
}

\section{HOW TO CITE THIS ARTICLE:}

Hardeep Singh Deep, Jeetesh Jain, Anumeet S. Grover. "Primary Biliary Cirrhosis association with Rheumatoid Arthritis: A Rare Case Presentation". Journal of Evolution of Medical and Dental Sciences 2014; Vol. 3, Issue 40, September 01; Page: 10117-10119, DOI: 10.14260/jemds/2014/3312

ABSTRACT: RA is present in about $1 \%$ of the population and PBC is even rarer, with an estimated prevalence of 20/100,000 for woman and 2/100,000 for men and the association of both diseases by chance is very unusual. We report a rare association between primary biliary cirrhosis and rheumatoid arthritis.

KEYWORDS: Primary biliary cirrhosis, rheumatoid arthritis, methotrexate, ursodeoxycholic acid

INTRODUCTION: Primary biliary cirrhosis (PBC) is characterized by portal inflammation and necrosis of cholangiocytes in small- and medium-sized bile ducts. Medium and small bile ducts are infiltrated with lymphocytes and undergo duct destruction. Mild fibrosis and sometimes bile stasis can occur.

Rheumatoid arthritis (RA) is a chronic inflammatory disease of unknown etiology marked by a symmetric, peripheral polyarthritis. These two conditions are in fact multi systemic diseases with a multitude of manifestations that are not limited to their target end organ. It has been well established that patients with PBC may have musculoskeletal complaints and patients with RA may have evidence of hepatic dysfunction. PBC is rare and the association of both diseases by chance is very unusual.

CASE REPORT: A 36 year old female was admitted in the department of medicine with the complaints of generalized itching, fatigue for five years and weight loss for one year (Fig. 1). Itching was more in the legs and the genital region (Fig. 2). History of pain and swelling in metacarpophalangeal and proximal inter phalangeal joints of both hands and early morning stiffness was also present. On examination, liver was palpable by $3 \mathrm{cmsbelow}$ the right costal margin, was of firm consistency with regular borders. There were hyper pigmented and lichenified lesions in the lower limbs and xanthelasma around the eyes (Fig.3). Small joints of the hands were swollen and tender.

INVESTIGATIONS: Hemoglobin 11.5g/dl; Prothrombin time 14/15s, Serum Bilirubin $1.1 \mathrm{mg} / \mathrm{dl}$, direct $0.65 \mathrm{mg} / \mathrm{dl}$, Serum AST $135 \mathrm{Iu} / \mathrm{l}$, Serum ALT $187 \mathrm{Iu} / \mathrm{l}$, Serum Alkaline Phosphatase 716Iu/l, GGT 210U/L serum proteins $6.2 \mathrm{~g} / \mathrm{dl}$ (albumin 3.8); blood urea $22 \mathrm{mg} / \mathrm{dl}$, serum creatinine $0.6 \mathrm{mg} / \mathrm{dl}$. Serum HIV, HBsAg, IgM anti-HAV and HCV antibodies were negative. Ultrasonography Abdomen showed enlarged liver $(16.5 \mathrm{~cm})$ with homogenous pattern with enlarged prominent spleen of $12.5 \mathrm{~cm}$ with normal echo pattern.

Anti- nuclear antibody (ANA), Anti Liver Kidney Microsomal (LKM) anti-bodies and Antismooth muscle antibodies (SMA) were negative. Anti-mitochondrial (M2 antigen) antibodies (AMA) were positive. ESR was $66 \mathrm{~mm} / \mathrm{hr}$ and CRP was $40 \mathrm{mg} / \mathrm{L}$. Rheumatoid factor was positive and anti 
CCP was 70U/L. The patient was initially started on cholestyramine powder $10 \mathrm{gm}$ and ursodeoxycholic acid at $15 \mathrm{mg} / \mathrm{kg} /$ day in divided doses. The itching subsided in two weeks but the fatigue persisted.

The patient was then started on methotrexate for RA. The patient is being followed up regularly. The side effects of cumulative dose of methotrexate are known and ultimately patient will require shift to other DMARDs.

DISCUSSION: The current case highlights the rare association between two immune mediated disorders. The patient had previously consulted several dermatologists before finally coming to the medicine department. The patient had no history of jaundice in her entire life. It was the raised ALT, AST and alkaline phosphatase which helped to consider cholestatic disorder. The diagnostic criteria of PBC includes biochemical evidence of cholestasis such as elevated alkaline phosphatase (ALP) and GGT, presence of disease-specific anti-mitochondrial antibodies and histological features of PBC.

The patient fulfilled two of the three criteria required currently for diagnosis of PBC. $(1,2)$

RA is present in about $1 \%$ of the population and PBC is even rarer, with an estimated prevalence of 20/100, 000 for woman and 2/100, 000 for men and the association of both diseases by chance is very unusual. (3) However, there are some reports describing its association in individuals/families.(4,5) In one series of 42 patients with PBC, four presented symptomatic arthritis with rheumatoid factor positivity.(6)

A study done by Sherlock and Scheuer (7) on 5\% of a cohort of 100 PBC patients had concomitant RA, with approximately $50 \%$ of PBC patients being positive for rheumatoid factor (RF). A study by Eli GM ${ }^{(8)}$ found 2 seropositive rheumatoid arthritis patients among 36 of Primary biliary cirrhosis patients. All these studies have reported association between primary biliary cirrhosis and rheumatoid arthritis earlier also but the exact mechanism for their association is still to be determined.

\section{BIBLIOGRAPHY:}

1. Kaplan MM, Gershwin ME. Primary biliary cirrhosis. New England J Medicine.2005; 353 (12): p1261-1273.

2. Lindor KD, Gershwin ME, Poupon R, Kaplan M, Bergasa NV, Heathcote EJ. Primary biliary cirrhosis. Hepatology. 2009; 50 (1): p291-308.

3. Siegel JL, Luthra H, Donlinger J, Angulo P, Lindor K. Association of primary biliary cirrhosis and rheumatoid arthritis. J Clin Rheumatol 2003, 9:p340-343.

4. Watt FE, James OF, Jones DE. Patterns of autoimmunity in primary biliary cirrhosis patients and their families: a population based cohort study. QJM 2004, 97:p397-406.

5. Caramella C, Avouac J, Philippe $S$ et al. Association between rheumatoid arthritis and primary biliary cirrhosis. Joint Bone Spine 2007, 74:p279-281.

6. Mills PR, Vallance R, Birnie G et al. A prospective survey of radiological bone and joint changes in primary biliary cirrhosis. Clin Radiol 1991, 32 (3): p297-302.

7. Sherlock S, Scheuer PJ. The presentation and diagnosis of 100 patients with primary biliary cirrhosis. New England J Medicine. 1973; 289 (13): p674-678. 


\section{CASE REPORT}

8. Ely GM, Perruguet JL, Newman ED. The arthritis of primary biliary cirrhosis: clinical features and associated immune processes. J Clin Rheumatol 1996Aug; 2 (4): p191-6.

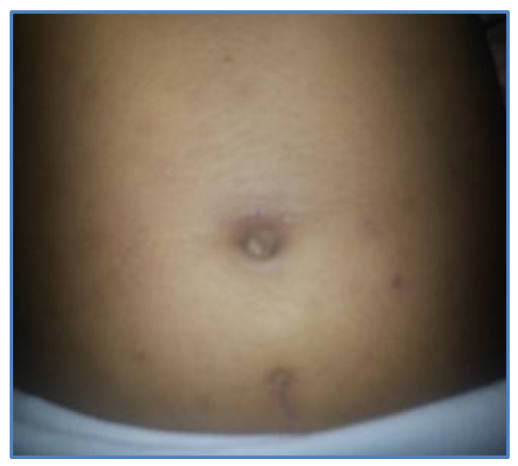

Figure 1

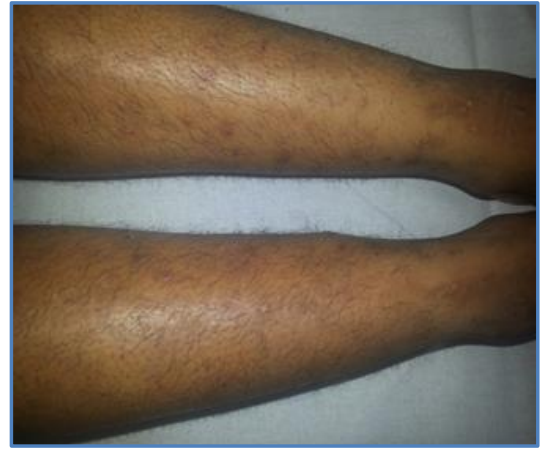

Figure 2

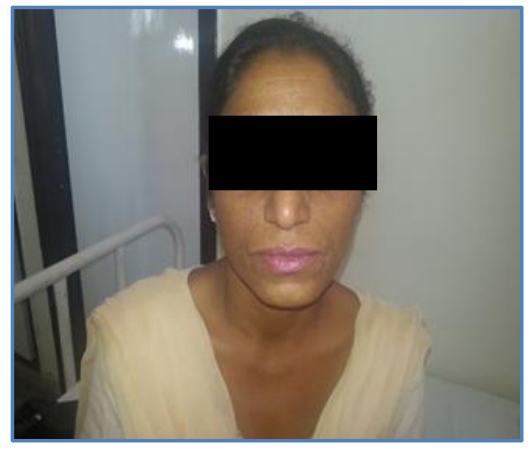

Figure 3

\section{AUTHORS:}

1. Hardeep Singh Deep

2. Jeetesh Jain

3. Anumeet S. Grover

\section{PARTICULARS OF CONTRIBUTORS:}

1. Professor, Department of Internal Medicine, Sri Guru Ram Dass Institute of Medical Sciences and Research, Vallah, Sri Amritsar.

2. Junior Resident, Department of Internal Medicine, Sri Guru Ram Dass Institute of Medical Sciences and Research, Vallah, Sri Amritsar.

3. Assistant Professor, Department of Internal Medicine, Sri Guru Ram Dass Institute of Medical Sciences and Research, Vallah, Sri Amritsar.

\section{NAME ADDRESS EMAIL ID OF THE CORRESPONDING AUTHOR:}

Dr. Hardeep S. Deep,

B-337 Ranjeet Avenue,

Amritsar-143001.

Email: deepak_tsr@yahoo.com

Date of Submission: 18/08/2014.

Date of Peer Review: 19/08/2014.

Date of Acceptance: 25/08/2014.

Date of Publishing: 30/08/2014. 